PONTIFÍCIA UNIVERSIDADE CATÓLICA DO RIO DE JANEIRO

O comportamento do consumidor jovem quanto ao lazer e consumo no Baixo Botafogo.

Naylane Gonçalves da Silva

Trabalho de Conclusão de Curso

Centro de CIÊnCIAS SOCIAIS - CCS

DEPARTAMENTO DE ADMINISTRAÇÃO

Graduação em Administração de Empresas 
Naylane Gonçalves

\section{O comportamento do consumidor jovem quanto ao lazer e consumo no Baixo Botafogo.}

Trabalho de Conclusão de Curso

Trabalho de Conclusão de Curso, apresentado ao programa de graduação em Administração da PUC-Rio como requisito parcial para a obtenção do titulo de graduação em Administração.

Orientadora: Paula Cunha

Rio de Janeiro, Dezembro de 2018. 


\section{Agradecimentos}

Agradeço a minha orientadora, professora Paula Cunha pela sua paciência, orientação e suporte para a realização deste trabalho.

Aos meus pais e familiares, agradeço pela energia positiva que me foi transmitida ao longo dos dias difíceis.

Aos meus amigos que me auxiliaram e muito me estimularam para a finalização do trabalho.

Agradeço também, com todo o meu amor e reconhecimento da importância dele na minha vida, ao meu avô, que hoje infelizmente já não está mais presente entre nós, mas que muito colaborou para o atual momento. 


\section{Resumo}

Silva, Naylane. O comportamento do consumidor jovem quanto ao lazer e consumo no Baixo Botafogo. Rio de Janeiro, 2018. 30 p. Trabalho de Conclusão de Curso - Departamento de Administração. Pontifícia Universidade Católica do Rio de Janeiro.

O tema da pesquisa visa entender o comportamento do consumidor jovem quanto ao lazer e consumo nos bares do Baixo Botafogo. A pesquisa busca identificar quais são estímulos que motivam esse público quando se levado em conta o consumo e escolha do estabelecimento de preferência no bairro. Com o propósito de identificar diferentes pontos, como: os perfis dos consumidores, os produtos ou serviços mais atrativos; foi realizada uma pesquisa de natureza qualitativa, por meio de entrevistas e observação no local. O público selecionado para a coleta de dados, está na faixa etária de 20 a 29 anos, de ambos os sexos, sendo residentes ou frequentadores de Botafogo, para melhor compreender o tema abordado.

Palavras-chave: Marketing, Comportamento do consumidor; Serviços; Jovens; Lazer; Bares; Restaurantes.

\section{Abstract}

Silva, Naylane. The behavior of the young consumer regarding leisure and consumption in the low Botafogo. Rio de Janeiro, 2018. 30 p. Course Completion Work - Administration Department. Pontifical Catholic University of Rio de Janeiro

The theme of the research is to understand the behavior of young consumers regarding leisure and consumption in bars of low Botafogo. The research seeks to identify which are the stimuli that motivate this public when taking into account the consumption and choice of preference establishment in the neighborhood. With the purpose of identifying different points, such as: the profiles of consumers, the most attractive products or services; a qualitative research was carried out, through interviews and observation at the site. The public selected for data collection, is in the age group of 20 to 29 years, of both sexes, being residents or frequenters of Botafogo, to better understand the topic addressed.

Key-words: Marketing, Consumer behavior; Services; Youth; Young consumers; Bars; Leisure; Recreation; Entertainment. 


\section{Sumário}

1 . Introdução 1

$\begin{array}{lll}1.1 & \text { Contextualização do problema } & 1\end{array}$

1.2 Relevância do estudo 3

1.3 Objetivo do estudo 5

1.4 Delimitação do estudo 5

2 . Referencial Teórico 6

2.1 Comportamento do Consumidor 6

2.1.1 Tomada de Decisão 8

$\begin{array}{lll}2.1 .2 & \text { Percepção } & 8\end{array}$

2.2 Entretenimento e Lazer 9

3 . Metodologia 10

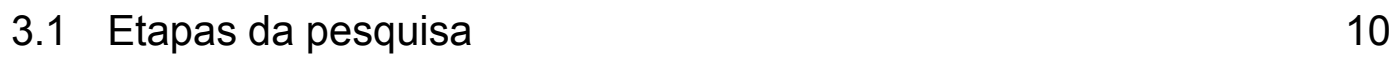

3.1.1 Etapa de mapeamento e concentração dos bares 10

3.1.2 Etapa de identificação da localidade a ser estudada 11

$\begin{array}{ll}\text { 3.1.3 Etapa: Tipo de pesquisa } & 12\end{array}$

3.1.4 Etapa de elaboração do roteiro de entrevista 13

3.1.5 Etapa: Seleção dos sujeitos e das entrevistas 13

4 . Apresentação e análise dos resultados 16

$\begin{array}{lll}4.1 & \text { Os estabelecimentos selecionados } & 16\end{array}$

4.2 A primeira experiência no BB (Baixo Botafogo) 17

4.3 Frequência de idas e atrativos da localidade 17

$\begin{array}{lll}4.4 & \text { As companhias } & 18\end{array}$

$\begin{array}{lll}4.5 & \text { Relação com o bairro } & 19\end{array}$

4.6 As percepções sobre o serviço 20

5 . Conclusões 21

$\begin{array}{lll}5.1 & \text { Sugestões pra futuras pesquisas } & 22\end{array}$ 


\section{Lista das imagens}

Imagem 1: Mapa do bairro de Botafogo e a concentração dos bares ............... 2

Imagem 2: Alfa Bar e Alice Bar.............................................................. 11

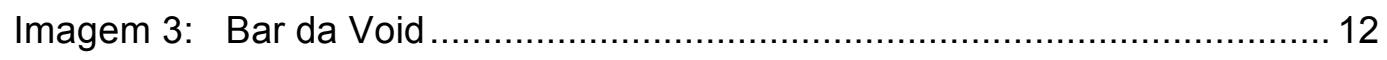

\section{Listas das tabelas}

Tabela 1: Caracterização da amostra............................................................ 14

Tabela 2: Resultado dos entrevistados. ....................................................... 19

Tabela 3: Resultado dos entrevistados. .................................................... 19 


\section{1 . Introdução}

O presente artigo foi elaborado abordando o tema do comportamento do consumidor jovem carioca e a sua percepção de valor na tomada de decisão quanto ao consumo em bares e restaurantes do bairro de Botafogo, na zona sul do Rio de Janeiro.

\subsection{Contextualização do problema}

Segundo uma matéria disponível no site da Veja, de 19 de Janeiro de 2017, só na cidade do Rio de Janeiro são encontrados cerca de 14 mil bares e restaurantes. Sites de buscas por esse tipo de estabelecimento, como o TripAdvisor, dispõem de 13.069 estabelecimentos cadastrados somente no Rio e algo em torno de 573 concentrados apenas em Botafogo ${ }^{1}$. Ainda sobre a matéria da Veja Rio, são encontrados relatos dos proprietários dos estabelecimentos mais antigos do lugar, onde os mesmos falam sobre o aumento significativo notado por eles quanto ao consumo nos últimos anos, além de um surgimento cada vez uma maior de estabelecimentos do mesmo setor.

Botafogo é conhecido por ser um bairro tradicional, além de ser famoso pelos seus diversos polos gastronômicos, que nos últimos anos vem apresentando um crescimento importante nesse mesmo segmento de mercado e uma maior distribuição dos mesmos. Três diferentes localidades tiveram grandes destaques e bom desenvolvimento ultimamente, como a Rua Nelson Mandela, os bares da Rua Voluntários da pátria e a concentração de estabelecimentos do mesmo ramo na Rua Capitão Salomão e Rua Visconde Silva. Todos os três locais, mesmo que pertencentes ao bairro, possuem suas particularidades, como os diferentes públicos, propostas e serviços oferecidos.

Planejada e inaugurada em 2009, a Rua Nelson Mandela é composta por doze estabelecimentos, entre eles bares famosos, lanchonetes e restaurantes com nomes bem reconhecidos. O fato da localidade ser privilegiada pela proximidade do metrô do bairro e centros comerciais ao redor, faz o lugar ser altamente frequentado diariamente, sendo notável tal frequência pelas diversas mesas espalhadas pelas calçadas ao longo da via, todos os dias da semana. Aliás, essa é uma característica importante dos bares do lugar. Assim como na

${ }^{1}$ Dados retirados do próprio aplicativo do TripAdvisor quando se pesquisado sobre bares no Rio de 
Nelson Mandela, os estabelecimentos da Voluntários da pátria, localidade também conhecida como Baixo Botafogo (nome que remete ao famoso Baixo Gávea) também possui a distribuição de mesas espalhadas pela rua. Porém, ao contrário da proposta anterior, com um grau maior de sofisticação, os bares e restaurantes do Baixo Botafogo são voltados para um público mais popular e que buscam por um preço mais acessível. Em contrapartida, os quatro famosos bares da Capitão Salomão se misturam com esses dois padrões. Sendo lugares famosos pelas promoções de bebidas e happy hours, a localidade também chama atenção do público pela alta gastronomia e shows recorrentes, que costumam lotar as ruas nos bares como o Boteco Fusca, Aurora, Cumpadres e O plebeu.

Como citado anteriormente, sendo conhecido pelo novo bairro dos "Baixos", Botafogo também apresenta outros pontos importantes, como: a Rua Sorocaba, que após a chegada do Comuna e seus premiados hambúrgueres, estimulou a alta frequência de consumidores por ali, trazendo junto o interesse de investidores e culminando na abertura de bares concorrentes na mesma rua, como o renomado vizinho Alice Bar, especializado em drinks, o Alfa Bar e Yolo, famoso pelo seu cachorro-quente. Além, da Rua Farani, que tem como ponto positivo a proximidade as faculdades Facha, Santa Úrsula, FGV e IBMR, e que por sua vez, apostam em diferentes propostas, desde os bares mais tradicionais até espaços com comida japonesa e cerveja artesanal.

Antes de fato definir a localidade a ser estudada e observada, outras duas etapas foram bem importantes para a pesquisa. Através de buscas em redes sociais, sites e reportagens sobre os lugares que mais vinham se destacando, quatro pontos foram mais citados, são eles: Rua Nelson Mandela, Rua Capitão Salomão, Rua Voluntários da Pátria (BB) e Rua Sorocaba. A partir dessa descoberta, em duas idas até os lugares, observações foram feitas para a seleção do local que mais se concentravam o público a ser estudado, chegando a um resultado favorável ao Baixo Botafogo/ou Rua Voluntários da Pátria. 
Imagem1: Mapa do bairro de Botafogo e a localidade escolhida a ser estudada.

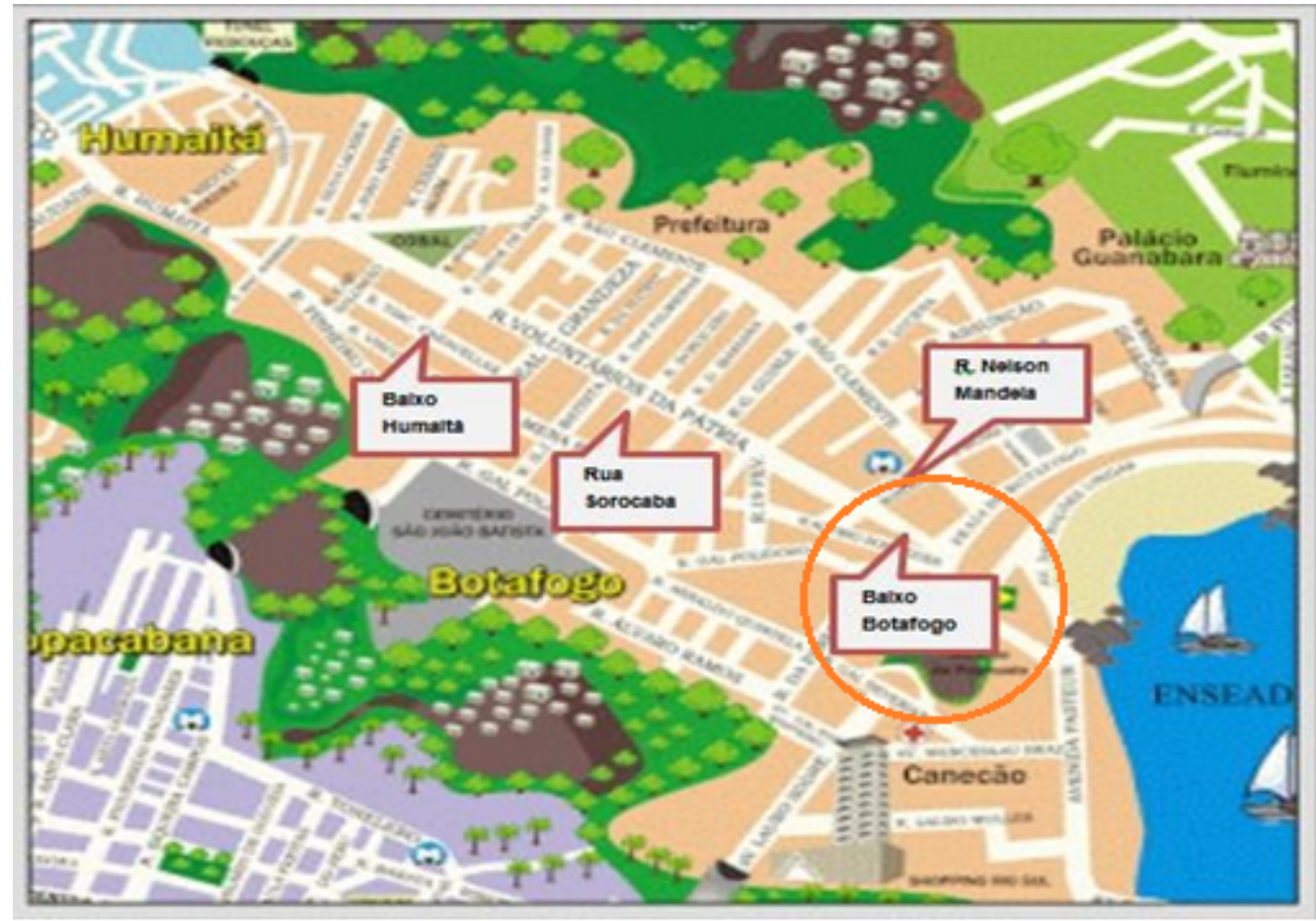

Fonte: Retirada do site urbecarioca.com.br/2012/05/botafogo-benesse-urbanistica-a- caminho.html, e editada pela autora do trabalho, indicando as localidades.

Como moradora do bairro, é notável que a realidade do mesmo não seja boa quanto ao tema segurança nos últimos anos, porém, de acordo com o site da Veja Rio de 14 de Janeiro de 2017, o mesmo relata que desde 2014 mais de trezes investimentos em empreendedorismo imobiliário foram iniciados na região, além de uma alta valorização do metro quadrado. De acordo com mesma matéria citada anteriormente, todos os números apresentados por ela, tiveram como base o Secovi Rio (Sindicato da Habilitação do Rio de Janeiro), onde o mesmo também indica um crescimento no valor do metro ${ }^{2}$ de $2,9 \%$ na Rua Dezenove de Fevereiro, 6,1\% na Rua Arnaldo Quintela e 9,1\% na Rua General Polidoro, todas elas com restaurantes renomados. Ao longo da mesma reportagem, são tidos outros depoimentos de frequentadores e investidores do local, onde segundo as editoras responsáveis pela obtenção dos relatos, Carol Zappa e Renata Magalhães, afirmam que houve uma mobilização por parte dos antigos estabelecimentos do bairro, que por sua vez, não estavam preparados para a grande ebulição do consumo atual. Segundo depoimentos concedidos às editoras da Veja Rio em Janeiro de 2017, proprietários afirmam que até os botecos mais antigos estão se preocupando com o nível da concorrência, e com isso, investindo mais em música ao vivo, karaokê e promoções no fim de tarde. Além, das invasões estrangeiras, também citadas pelos entrevistados pela revista anterior, onde o surgimento de bares com conceitos internacionais vêm apostando na localidade, que por sua vez, também possui uma alta concentração de estrangeiros espalhados pelos diferentes Hostels do bairro. 


\subsection{Relevância do estudo}

Pela ótica de gestores e comerciantes responsáveis por estabelecimentos que promovam o lazer ao consumidor, o tema se torna interessante justamente quando analisadas as variáveis que mais estimulam o público do bairro e as oportunidades que vem surgindo ao longo do tempo com a expansão do lugar, para os mesmos. Através de um estudo prévio, tendo como temas discutidos e abordados, pontos comuns àquele determinado segmento de consumidores, como, por exemplo, a qualidade do serviço oferecido, a localidade, os perfis dos consumidores ou que mais chama atenção do mesmo, se torna possível aprofundar-se um pouco mais sobre a compreensão desse mesmo público quanto a sua tomada de decisão de compra, de escolha do lugar e até mesmo da quantidade do consumo, mesmo que se tratando de uma pequena amostra dentro deste vasto segmento estudado.

Outro ponto que pode ser melhor estudado e compreendido pelos administradores, está justamente ligado aos novos conceitos dos bares e seus destaques. Mesmo com o conceito de tecnologia e avanços da mesma muito em alta, qualquer que seja o tamanho da empresa ou instituição, não anula concorrência ou produtos similares disponíveis para consumo, além de compradores dispostos a buscarem por preços mais justos (KOTLER, 2008). A concorrência de marcas se dá a partir do entendimento de uma empresa de acordo o com a atuação de suas concorrentes, enxergando-as como empresas que oferecem produtos e serviços semelhantes aos mesmos clientes e por preços e serviços similares. Ou seja, mesmo que a finalidade de um bar não venha a ter grandes variações, novos conceitos, estreitamento de laços ou apropriação de características de um determinado grupo, são estratégias utilizadas recentemente por alguns administradores para se aproximar de uma parcela dentro do seguimento de consumidores. A partir disso, o público consegue melhor se identificar e se relacionar com a proposta do lugar ou marca, destaque de importância para o bar, principalmente quando se aplicado a um ambiente onde existe uma alta concentração do mesmo, como Botafogo.

Como introduzido anteriormente, um ponto relevante a ser tratado com determinada importância são os investimentos em estabelecimentos do bairro em questão, onde diferentes conceitos e serviços são propostos, pois muitos são os públicos encontrados e perfis totalmente diferentes. A partir da expansão do lugar, diferentes características estão presentes na realidade da região, o que faz com que o ambiente esteja cada vez mais alinhado com os perfis dos consumidores, independente de renda, sexo, idade ou necessidades. Com o conceito de consumo acelerado, que é defendido por Schweriner (2008), parte do princípio que esse tipo de consumo se adapta bem as empresas que desejam estar devidamente alinhadas as suas situações financeiras oriundas de seus 
resultados com propagandas. Entende-se que dessa maneira os produtos e serviços venham a se tonar mais atraentes e imprescindíveis ao cliente.

\subsection{Objetivo do estudo}

O estudo tem como objetivo avaliar os diferentes comportamentos do consumidor quanto ao consumo de lazer do público jovem nos bares em expansão do bairro de Botafogo, na zona sul do Rio de Janeiro.

Buscando atingir o determinado objetivo, se fez necessário pré-estabelecer objetivos intermediários, como:

- Identificar as diferentes propostas de lazer oferecidas não só pelos bares do bairro em ocasião, mas por toda aquela área;

- Levantar dados a partir da observação do comportamento do consumidor ao longo de diferentes datas e situações;

- Identificar os principais pontos junto com os consumidores que poderiam vir a estimular ou não a frequência em determinado estabelecimento;

- Definir qual a localidade dentro de Botafogo que melhor apresentasse a situação escolhida;

\subsection{Delimitação do estudo}

O estudo destina-se a comparar o comportamento do consumidor jovem carioca com a distribuição dos distintos bares localizados em Botafogo e entender o quais são os estímulos para o consumo de lazer na região do BB (Baixo Botafogo).

As amostras foram restritas às pessoas que estavam presentes em um dos três dias de visitação ao local. Foram abordados consumidores de ambos os sexos, dentro da faixa etária de 20 a 29 anos, pertencentes a diferentes estilos e grupos e frequentadores de diferentes estabelecimentos.

A pesquisa visa identificar as reais motivações que levam o público a consumir e frequentar o lugar de acordo com a oferta de lazer proposta. Contudo, o estudo se restringe a uma pequena amostra de pessoas, o que não comprova que tal resultado seja suficiente para simbolizar toda uma população de consumidores. 


\section{2 . Referencial Teórico}

Neste capítulo são apresentados e discutidos aspectos conceituais e estudos relacionados ao tema e estudo em investigação e que servirão de base para a análise realizada.

Essa etapa está subdividida em quatro partes, onde respectivamente o conceito de comportamento do consumidor será abordado de maneira a contextualizar o processo de compra, além da discussão sobre os tipos de tomada de decisão do consumidor.

Outro ponto debatido será sobre a percepção de valor do consumidor quanto aos processos de consumo e quais as influencias podem afetar o comportamento do mesmo, além do conceito de entretenimento que abrange o tema estudado como um todo.

\subsection{Comportamento do Consumidor}

O comportamento do consumidor é a área responsável pelo estudo sobre como organizações, grupos e pessoas selecionam, compram, usam e descartam determinados produtos, serviços, ideais ou experiências para satisfazer seus desejos e necessidades existentes. De maneira geral, se trata de um processo onde só ocorre a partir de uma necessidade ou desejo por parte do consumidor. A partir desse estudo é possível entender o processo de decisão de compra e determinar as suas diferentes técnicas. (KOTLER, 2008)

E segundo ENGEL (2000), diariamente os consumidores são expostos a tomar decisões relacionadas à compra e seus processos, desde descarte, reciclagem ou até revenda. O modelo de comportamento de Engel, Blackwell e Miniard, que teve início em 1968 e, que posteriormente, seria revisado pelas próximas décadas, visa compreender determinadas fases desse processo, são elas: o reconhecimento da necessidade por parte do indivíduo, a busca por informações, avaliação de alternativas, compra, consumo, relação pós-compra e descarte.

Cordeiro (2006) entende que o marketing de modo geral é uma ferramenta de análise de grande importância para o processo do comportamento do 
consumidor a fim de buscar satisfazer as necessidades e desejos dos consumidores, através de ações de marketing, produtos e serviços que estimulem os mesmos ao consumo.

Segundo Solomon (2016), muitas das decisões de compra são influenciadas por grupos ou indivíduos presentes no cotidiano, seja através de conversas onde contêm inúmeras informações sobre determinado produto, bem como recomendações para as melhores marcas. O autor cita o surgimento de comunidades de consumo, onde consumidores compartilham pontos de vista e recomendações de variados serviços, produtos, aplicativos e lugares.

Para Solomon (2016), determinadas variedades demográficas são fundamentais para que tornem os consumidores iguais ou diferentes uns dos outros, são elas:

- Idade: o autor entende que consumidores de diferentes faixas etárias têm necessidades e desejos distintos, e mesmo os que pertencem a uma mesma faixa etária diferem em muitosaspectos;

- Gênero: a diferenciação por gênero sempre muito exposta quanto ao setor de marketing, onde muitos produtos ainda são classificados em rosa para mulheres e azul para os homens;

- Estrutura familiar: variável apontada como uma das mais importantes justamente pelo fato da mesma conseguir imprimir as prioridades de gastos dos consumidores.

- Classe social e renda: proximidade quanto aos termos de renda e posição social. Grupos podem ser aproximados por exercerem atividades e práticas semelhantes para música, vestuário ou atividades de lazer.

- Raça e etnicidade: com uma sociedade cada vez mais multicultural, a oportunidade de surgimento de espaços, produtos e serviços especializados em grupos étnicos se torna cada vez maior.

- Geografia: empresas nacionais que apresentam ofertas para justamente atrair consumidores que vivem em outros países.

- Estilo de vida: cada indivíduo apresenta seu estilo de vida, mesmo que pertencentes a uma mesma variável demográfica em comum, como gênero. 


\subsubsection{Tomada de Decisão}

Trata de um processo onde o consumidor passa por determinadas etapas até a decisão de compra (KOTLHER, 2008). Estudiosos do marketing desenvolveram um certo modelo de etapas desse processo, onde se tem início bem antes da real ação de compra, e consequências no pós-consumo. No total são cinco etapas até a tomada de decisão, porém nem sempre todos os indivíduos costumam passar por todas as cinco, são elas:

Reconhecimento do problema: onde o processo de compra começa quando se entende uma necessidade/demanda.

Busca por informações: quando o consumidor busca por mais informações sobre o produto ou serviço.

Avaliação das alternativas: depois do processamento de todas as informações buscadas, o consumidor faz um julgamento final, criando preferencias entre as marcas.

Decisão de compra: o momento em que o consumidor forma uma intenção de compra, após as pesquisas.

Comportamento pós-compra: aspectos percebidos pelo consumidor, após a experiência de consumo do mesmo, podendo ser classificada como: satisfatória ou não. (KOTLHER, 2008)

\subsubsection{Percepção}

Percepção é o processo de seleção, organização e interpretação de sensações (Solomon, 2016). O entendimento e o processamento das informações diferenciam de um indivíduo para o outro, podendo influenciar ou não na tomada de decisões e no processo de compra. A percepção pode sofrer influência através de três fatores básicos: fatores situacionais, quando ligados ao momento de compra; os fatores relacionados ao serviço ou produto e os fatores ligados diretamente ao consumidor, como as suas necessidades, motivações, interesses e experiências anteriores.

A percepção está diretamente ligada a relação do indivíduo e o meio ambiente, o que parte do princípio que ela nada mais é, do que o processo de decodificação de informações e estímulos externos pertencentes ao meio. 


\subsection{Entretenimento e Lazer}

Segundo o autor Bucci (2006), o entretenimento é entendido como algo que acontece num determinado tempo de lazer, nas horas vagas, passatempo ou no intervalo entre duas atividades ditas sérias. Subentendesse que tanto o conceito de entretenimento quanto o de lazer estejam próximos um do outro.

A palavra lazer vem do latim "licere", ou seja, ser lícito, correto, legítimo. $E$ tem como definição as ações que o indivíduo pode exercer em seu tempo livre e que the proporciona prazer. Dentro do contexto, seria o tempo dedicado a descanso, recreação e relaxamento (Santana, 2012).

De acordo com Dumazedier (2009), são seis os grupos dentro do lazer. São eles: intelectuais, artísticos, os manuais, sociais, esportivos e os turísticos. Dentro da perspectiva abordada, destacamos o lazer social, onde estão diretamente ligados ao convívio, contato social e aos relacionamentos em festas, bares, recepções e diferentes pontos de encontro. 


\section{3 . Metodologia}

Este capitulo visa descrever e informar todas as etapas do processo de coleta de dados para a pesquisa do estudo do caso. O mesmo está dividido em seções que identificam, o tipo de pesquisa que foi feita, o ambiente a ser estudado e os diferentes perfis dos entrevistados.

\subsection{Etapas da pesquisa}

O método adotado no estudo obedeceu a seguinte sequência de etapas:

\subsubsection{Etapa de mapeamento e concentração dos bares}

Visando identificar o maior número possível de bares e suas formas de lazer espalhadas por Botafogo, foram feitas pesquisas rápidas em sites/noticiários/redes sociais e entre alguns consumidores, que por sua vez tinham o mesmo perfil estudado. Nesse levantamento, os 8 participantes foram questionados sobre quais os locais dentro do bairro eles julgavam ter uma maior concentração de consumidores jovens, assim como eles.

Com o resultado de coleta de dados, quatro localidades foram citadas, são elas:

- Rua Nelson Mandela - também conhecida pelos frequentadores como "Rua Nova" perto da estação do metrô;

- Baixo Humaitá - o encontro dos quatro bares (Boteco Fusca, Cumpadres, O Plebeu e Aurora) na esquina da Rua Capitão Salomão e Rua Visconde de Silva;

- Baixo Botafogo - a concentração dos quatorze bares no início da Rua Voluntários da Pátria;

- Rua Sorocaba - com os tradicionais Comuna e Alice Bar 
Imagem 2: Alfa Bar e Alice Bar - Rua Sorocaba

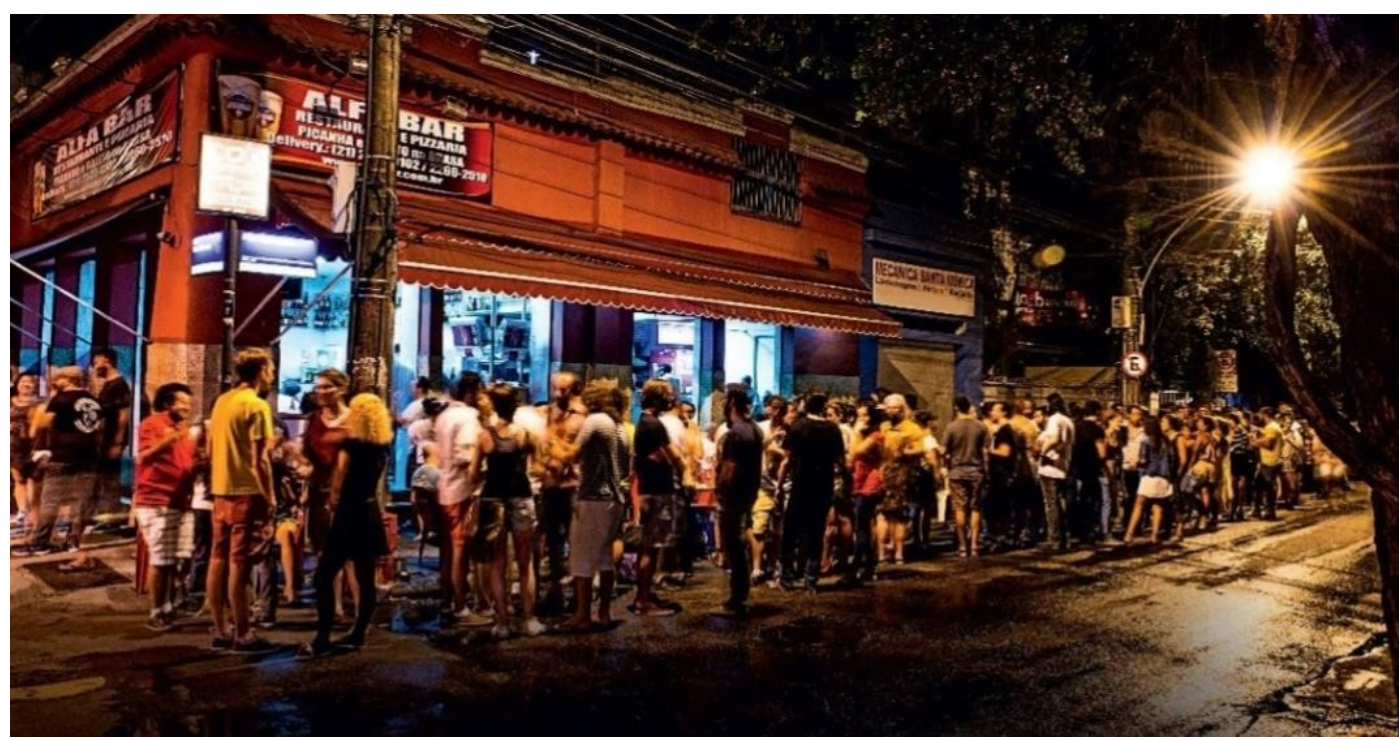

Fonte: VEJA RIO - Comer \& Beber 2018/2019: Bares Zona Sul

\subsubsection{Etapa de identificação da localidade a ser estudada}

A partir dos resultados da primeira etapa do processo de identificação da maior concentração de jovens consumidores no bairro, foi necessária uma escolha entre as quatro áreas citadas na pesquisa anterior.

O método escolhido nessa etapa foi o da observação participante. Durante o mês de Setembro nos dias 15 (sábado) e 21 (sexta-feira), observações e anotações foram feitas sobre a movimentação e concentração de grupos nos locais. Esse tipo de abordagem é usada por pesquisadores da área de Marketing e Design como uma forma de obter uma compreensão de situações de consumo e de uso de produtos. A ideia é, de certa forma, se colocar também na perspectiva do pesquisado para tentar compreender melhor como ele se comporta, pensa e sente no contexto estudado. (PINHEIRO e ALT, 2017)

De acordo com a distribuição de consumidores e um maior acúmulo do público-alvo, foi escolhida a área de estudo do Baixo Botafogo. 
Imagem 3: Bar da Void

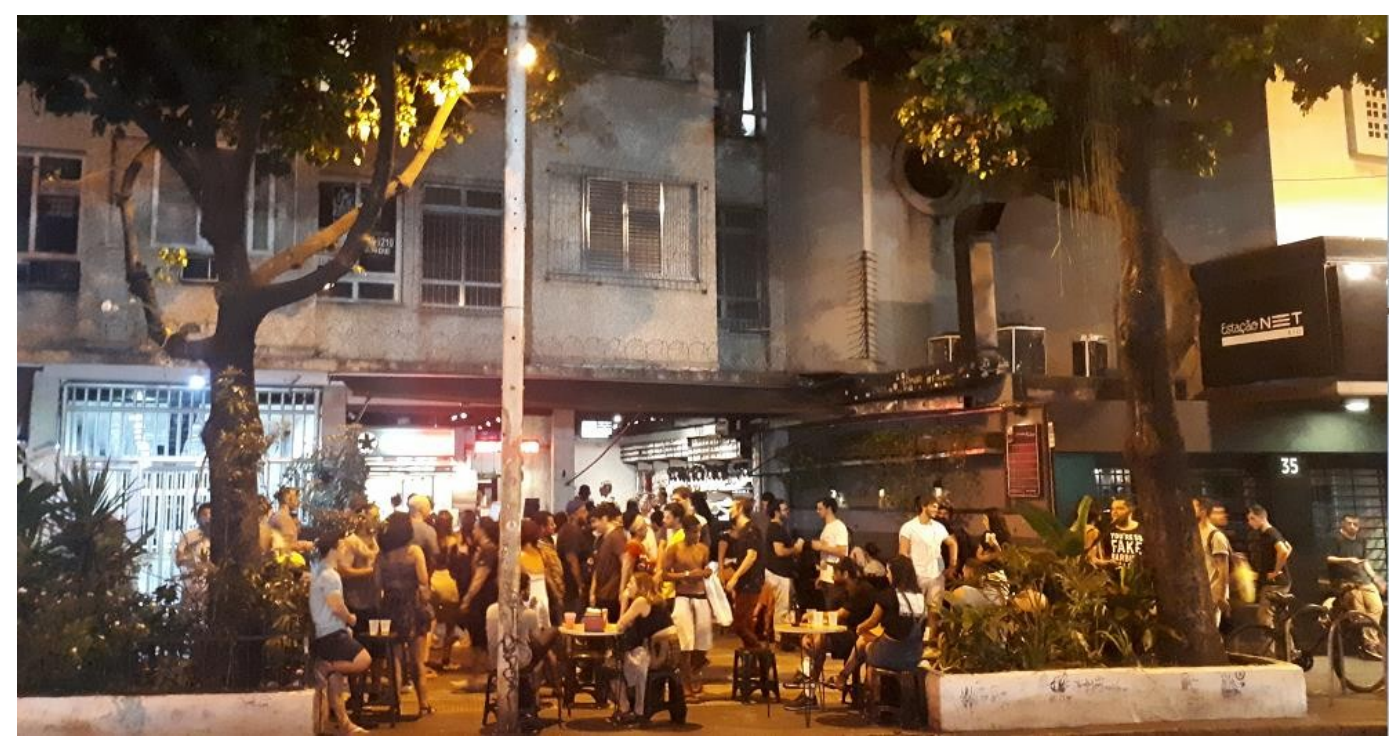

Fonte: Foto retirada pela autora na data 20 de Outubro de 2018.

\subsubsection{Etapa: Preparação para a pesquisa}

Depois de identificada a área de estudo, foi necessário buscar um tipo de pesquisa onde a mesma conseguisse reter a maior quantidade possível de informações dos entrevistados.

Com a intenção de levantar dados sobre o assunto e uma futura análise dos resultados, foi realizada uma pesquisa de natureza exploratória, usando como método para a coleta de dados, a pesquisa qualitativa. Os mesmos foram coletados por meio de entrevistas individuais com o público, realizadas na própria localidade objeto do estudo, ou seja, na área em que ficam os bares e estabelecimentos do baixo Botafogo.

Segundo Godoy (1995) sendo classificada como qualitativa, a pesquisa considera o ambiente como fonte direta de dados, e o pesquisador, por sua vez, como um instrumento chave para a interpretação dos resultados, de tal maneira onde a análise dos dados é indutiva e intuitiva, sem a interferência do mesmo.

A opção por uma pesquisa qualitativa se deu tanto em função de ser um fenômeno relativamente novo naquela região e sobre o qual não se identificou pesquisas anteriores, bem como pelo fato de que o interesse no presente estudo foi de compreender melhor como e por que as pessoas se sentem atraídas a frequentar aquele ambiente, levantando uma série de hipóteses para tal.

A partir disso, a abordagem por meio de entrevistas com os frequentadores, complementada pela observação do lugar em dias distintos se mostrou adequada na medida em que permitiria uma melhor compreensão naquela realidade e ter uma perspectiva mais próxima à dos próprios 
participantes, no que seria uma abordagem mais imersiva ou etnográfica, num modo mais simplificado.

Como auxílio para a realização das entrevistas, foi estruturado primeiro um roteiro, no qual eram abordados diferentes pontos de relevância para o estudo, como, dados pessoais do grupo/ou do indivíduo entrevistado, frequência no local, localização, percepção do público, experiências antigas, o tipo de companhia, serviço oferecido e sobre o espaço.

Para a análise dos dados recolhidos, foram feitas as categorizações das informações recolhidas quanto aos temas abordados pelos envolvidos.

Segue o roteiro utilizado nas entrevistas:

\section{Pesquisa Qualitativa - o comportamento do consumidor jovem quanto ao lazer e consumo no Baixo Botafogo.}

\section{(APRESENTAÇAO do TEMA E PESSOAL - PEDIR PERMISSÃo PARA GRAVAÇÃo)}

Identificação: Nome, Idade, Endereço

Sobre o lugar:

- Como foi a sua primeira experiência no lugar?

- Como conheceu? E desde quando frequenta?

- Sua frequência? Costuma variar com a época do ano/mês/semana?

- Com quem costuma ir até o lugar?

- Quando vai até o BB, você convida oué convidado?

- O que te chama mais atenção?

- Porque Botafogo e não outros bairros?

- Faz dessa ida até o lugar um "programa" ou apenas uma "pré"?

- O que acha do atendimento?

- O que para vocêfaz o Baixo Botafogo ser um atrativo aos jovens?

- O que que você acha do público? (Perfil, idade, gosta?)

- Faria alguma melhoria ou sugestẫo para o local ou estabelecimentos?

\subsubsection{Etapa: Seleção dos sujeitos e das entrevistas}

A pesquisa foi realizada no mês de Setembro e Outubro de 2018, com 24 jovens na faixa etária de 20 e 29 anos, que têm como costume frequentar os bares e restaurantes no bairro de Botafogo, principalmente na localidade do Baixo Botafogo, na Rua Voluntários da Pátria. Na pesquisa, ambos os sexos foram entrevistados, e não houve uma limitação quanto a classe social do entrevistado ou o seu poder aquisitivo, justamente com a finalidade de identificar 
quais os públicos estão ali presentes na rotina do lugar, além dos seus hábitos e comportamentos.

$\mathrm{Na}$ tabela a seguir, o perfil total da amostra obtida:

Tabela 1: Caracterização da amostra

\begin{tabular}{|c|c|c|c|}
\hline Entrevistados & Idade & Bairro onde reside & Data da entrevista \\
\hline Fernanda Teixeira & 24 & Barra & $27 / 09 / 2018$ \\
Guilherme Santos & 29 & Botafogo & $27 / 09 / 2018$ \\
Laura Gabaglia & 21 & Botafogo & $27 / 09 / 2018$ \\
Luíza Araújo & 25 & Lagoa & $27 / 09 / 2018$ \\
Nathália Luzes & 24 & Tijuca & $27 / 09 / 2018$ \\
Renata Bella & 25 & Botafogo & $27 / 09 / 2018$ \\
Renata Silva & 24 & Botafogo & $27 / 09 / 2018$ \\
\hline André Machado & 27 & Copacabana & $12 / 10 / 2018$ \\
Bernardo Saba & 23 & Cosme Velho & $12 / 10 / 2018$ \\
Leon Barbosa & 25 & Flamengo & $12 / 10 / 2018$ \\
Maria Santa & 22 & Botafogo & $12 / 10 / 2018$ \\
Mariana Carrilho & 20 & Botafogo & $12 / 10 / 2018$ \\
Marina Maria & 23 & Botafogo & $12 / 10 / 2018$ \\
Roger Mendes & 26 & Botafogo & $12 / 10 / 2018$ \\
Ronaldo Paz & 29 & Copacabana & $12 / 10 / 2018$ \\
Thais Montes & 29 & Botafogo & $12 / 10 / 2018$ \\
William Silva & 28 & Botafogo & $12 / 10 / 2018$ \\
Ylana Feijão & 22 & Copacabana & $12 / 10 / 2018$ \\
\hline Tauane Alves & 24 & Botafogo & $20 / 10 / 2018$ \\
Guiliana Menezes & 29 & Botafogo & $20 / 10 / 2018$ \\
Thayrine Alves & 23 & Botafogo & $20 / 10 / 2018$ \\
Germano Silva & 24 & Botafogo & $20 / 10 / 2018$ \\
Yasmim Pereira & 24 & Botafogo & $20 / 10 / 2018$ \\
Andressa Sergi & 28 & Tijuca & $20 / 10 / 2018$ \\
\hline
\end{tabular}

Fonte: Elaboração pela autora com base na pesquisa de campo.

A coleta de dados foi realizada no local de estudo, com abordagem direta aos participantes que estavam consumindo nos bares da Rua Voluntários da Pátria. Nessa etapa, três visitações foram realizadas e todas com o auxílio do roteiro e de um gravador (todas as entrevistas com autorização prévia de gravação e identificação de cada um dos participantes).

O primeiro dia de entrevista foi no dia 27 de Setembro de 2018, um a quinta-feira, e teve como início às $19 \mathrm{~h} 45 \mathrm{e}$ finalizou às $22 \mathrm{~h} 00$. Foram entrevistadas 7 pessoas ao longo da noite, do total 6 mulheres e 1 homem. Nesse primeiro momento, consumidores de três bares foram abordados, 
Durangos, Rosas de Ouro e Void. Em todas as abordagens, nenhum dos entrevistados estava sozinho, sempre acompanhado de um ou mais companhias. As informações foram obtidas no próprio ambiente e sem intervenção de algum dos indivíduos que também estavam na mesa.

No segundo dia 11 pessoas foram entrevistadas no feriado do dia 12 de Outubro de 2018, uma sexta-feira. As mesmas deram início às $18 \mathrm{~h} 22 \mathrm{e}$ terminaram às $23 \mathrm{~h} 45$ do mesmo dia. Dessa vez, foram ouvidos clientes de outros quatro estabelecimentos, como, o Sociedade Secreta, Marchezinho, Bar do Federal e Botequim Imperial. Seguindo a mesma linha do primeiro dia, nenhum dos clientes que se propuseram a responder as perguntas estava sozinho, porém dessa vez, foi possível se entrevistar toda uma mesa de uma única vez.

No último dia, 20 de Outubro de 2018, num sábado, outras 6 pessoas foram entrevistadas. Desta vez, diferente do segundo dia onde os homens foram maioria (6 homens $\times 5$ mulheres), a maioria também foi do público feminino, totalizando em 5 mulheres e 1 homem. Os bares que tiveram seus consumidores como participantes nessa última bateria de entrevistas, foram, Sollar Bar e Restaurante, Rosas de Ouro e Soho Bar. As abordagens deste dia começaram por volta das $21 \mathrm{~h} 18$ e terminaram às $00 \mathrm{~h} 45$, do dia 21 .

Importante ressaltar que vários dos processos, como, o de abordagem, permissões, gravações e registros, foram utilizados da mesma maneira em toda a etapa de pesquisa. 


\section{4 . Apresentação e análise dos resultados}

Sob a ótica de residente do bairro e frequentadora da grande maioria dos lugares abordados aqui pelo estudo, acredito que a área escolhida para as abordagens e tema da pesquisa, foi justamente a localidade aonde mais vem se desenvolvendo no bairro nos últimos anos, a do Baixo Botafogo. Ao longo das pesquisas e observações, conseguiu-se entender que se trata de um bairro muito familiar e que tem como característica, envolver a todos. Diferente de outros "points", Botafogo sabe agregar a todos os tipos de pessoas, gêneros, classes, tribos e estilos. Quando visto pela primeira vez, um verdadeiro aglomerado de pessoas distintas, que a principio tende a parecer desordenado, mas que com o passar do tempo, ali observando os envolvidos, chega-se a uma conclusão que só quem de fato está dentro deste mesmo aglomerado entende, todos ali de algum jeito se conhecem ou pertencem ao mesmo lugar, logo, estão no mesmo segmento.

Foram selecionados 24 consumidores, sendo eles frequentadores de todos ou de quase todos, os estabelecimentos do local. A partir desses resultados e suas categorizações, se permitiu chegar a diferentes conclusões e resultados.

\subsection{Os estabelecimentos selecionados}

Localizados logo no início da Rua Voluntários da Pátria, em Botafogo, são ao todo quatorze bares distribuídos em ambos os lados da rua. Com base nas observações feitas, quase todos os estabelecimentos têm como finalidade a mesma característica de consumo barato, a distinção por parte do consumidor acaba sendo decidida por outras variáveis. Diferente da grande maioria, a VOID é uma exceção, que por sua vez, tem como característica um ambiente mais estilizado e moderno, junto com uma loja que permite uma interatividade maior com o seu público. Além do investimento de diferentes eventos voltados para uma gastronomia diferenciada, acompanhando sempre as tendências do mercado, e se aproximando de um público que está sempre mais antenado as modernidades do setor. 
Outro bar que se diferencia da maioria, é o Rosas de Ouro, que diferente dos outros possui um horário de funcionamento mais longo ao longo do dia, ampliando para o público que também frequenta o lugar na hora do almoço, utilizando o serviço se self-service do lugar.

Mesmo tendo outras áreas com bares em foco, Botafogo se destaca como sendo um bairro de passagem para muitos. Segundo 22 dos entrevistados, eles também frequentam outros bares no mesmo bairro, porém a facilidade de locomoção tanto para chegar quanto para sair da Rua Voluntários da Pátria é muito mais acessível tendo a opção do metrô para de deslocar, do que os outros pontos, como Rua Capitão Salomão ou Sorocaba, principalmente àqueles que moram distante.

\subsection{A primeira experiência no BB (Baixo Botafogo)}

Quando se questionado aos entrevistados sobre o período em que começaram a frequentar ou sobre a primeira experiência no lugar, muitos não se recordaram com riqueza de detalhes, porém todos tiveram a mesma lembrança de serem levados até o local pelos amigos mais próximos.

O principal estímulo para grande parte da maioria começar a frequentar os bares de Botafogo foi para conhecer o diferenciado e atrativo bar da VOID. Só a partir da segunda ida até o "BB" (abreviação de Baixo Botafogo) que os consumidores tiveram a percepção do custo-benefício que o lugar oferecia e se transformaram em "público cativo", maneira como um grupo de jovens se classificou no momento de uma das entrevistas. .

\subsection{Frequência de idas e atrativos da localidade}

De acordo com a observação feita no local, a distribuição dos consumidores acontece sem que haja um padrão específico como se não existisse necessariamente uma preferência pelo melhor lugar ou pelo melhor serviço ali oferecido. Um ponto que chamou atenção foi pelo fato de se não observar grandes grupos chegando até os estabelecimentos durante a noite, mas não era necessário se esperar muito tempo para que uma significante concentração estivesse formada, de tal maneira como se quase todos ali se conhecessem. 
Algo que também despertou interesse, foi a constatação da grande maioria se apresentar em grupos, poucos eram os indivíduos sozinhos ou em casal. Tal ponto pode ser observado em todas as visitas ali realizadas. Assim como a diferenciação dos perfis presentes. A grande maioria concentrada são jovens de diferentes idades, estilos, endereços e de ambos os sexos. Ficou claro que não existe uma padronização quanto ao público e que todos buscam pela mesma oferta, a consumação mais barata e a concentração de amigos.

Dos 24 jovens entrevistados, 17 afirmaram que sempre estão na localidade pelo fato de ser um lugar onde eles podem obter, mesmo que por algumas horas, parte do seu dia de folga dentro de uma dura semana de trabalho, e que pelo fato de saber que os amigos também estão lá buscando o mesmo, faz com que seja uma semana mais tranquila. Por esse e outros motivos a ida até os bares da Voluntários se tornou uma espécie de hábito para a grande maioria.

Segundo alguns jovens ali reunidos, o fato da localidade ser um ambiente próximo ao trabalho de todos e da casa de alguns, fez com que um ritual fosse criado entre o grupo há quase 2 anos, onde toda quarta e sexta-feira eles estejam reunidos ali, independente do bar, para assistir aos jogos de futebol e comemorar mais uma semana de trabalho concluída.

Ao longo da semana e das outras visitas, foi possível verificar que não existe uma certa regularidade quanto a quantidade de clientes ou a distribuição dos mesmos. De acordo com os dados coletados, a escolha pelo lugar a ser frequentado acontece de diferentes maneiras, como por exemplo, quando a pessoa que convidou opta por um dos estabelecimentos $(100 \%$ dos entrevistados são convidados a ir até o local), ou de acordo com a vontade da primeira pessoa do grupo que chegou até o local ou simplesmente onde se tem mesa disponível.

\subsection{As companhias}

A pesquisa permitiu verificar algumas das informações que a própria observação já tinha detectado, o fato das pessoas estarem acompanhadas em grande parte por amigos. De acordo com as tabelas a seguir, em todas as 3 visitações no local, somando o número de entrevistados, $75 \%$ dos consumidores estavam acompanhados de amigos ou que citaram durante a entrevista que frequentam o lugar com esse tipo de público. Os outros $15 \%$ citaram que também vão ao BB, porém acompanhados pelo parceiro(a), namorado(a). 
Tabela 2: Resultado dos entrevistados

\begin{tabular}{|c|c|c|c|}
\hline \multicolumn{3}{|c|}{ Tabela de Dados } \\
\hline Visitação & Data & Dia da semana & $N^{\circ}$ de Pessoas \\
\hline $1^{\text {a }}$ & $27 / 09 / 2018$ & Quinta-feira & 7 \\
$2^{\mathrm{a}}$ & $12 / 10 / 2018$ & Sexta-feira & 11 \\
$3^{\mathrm{a}}$ & $20 / 10 / 2018$ & Sábado & 6 \\
\hline \multicolumn{3}{|c|}{ Total de entrevistados: } & 24 \\
\hline
\end{tabular}

Fonte: Elaboração pela autora com base na pesquisa de campo.

Tabela 3: Análise da frequência dos entrevistados

\begin{tabular}{|c|c|c|c|c|}
\hline \multicolumn{5}{|c|}{ Tabela de Frequência (Companhia) } \\
\hline Visitação & $\mathbf{N}^{\circ}$ de Pessoas & Amigos & Namorado & Sozinho \\
\hline $1^{\text {a }}$ & 7 & 5 & 2 & 0 \\
$2^{\text {a }}$ & 11 & 8 & 3 & 0 \\
$3^{\text {a }}$ & 6 & 5 & 1 & 0 \\
\hline Total & 24 & 18 & 6 & 0 \\
\hline Total em \% & $100 \%$ & $75 \%$ & $25 \%$ & $0 \%$ \\
\hline
\end{tabular}

Fonte: Elaboração pela autora com base na pesquisa de campo.

\subsection{Relação com o bairro}

Através da pesquisa foi possível identificar o grau de pertencimento que aqueles jovens possuem com o bairro. Durante a coleta de dados quando se questionado o motivo pelo qual eles optaram pelo bairro de Botafogo e não outros tão famosos quanto, todos os ali presentes demonstraram algum tipo de envolvimento com a região, foram citadas diferentes situações como: 62,5\% moram atualmente no bairro, então justificaram com a proximidade de casa; $25 \%$ têm amigos que moram em Botafogo e com isso faz com que seja um estímulo a frequentar os bares também; $29,16 \%$ já estudou em algum dos colégios da área; $8,33 \%$ comentou que algum familiar próximo reside no lugar e faz com que seja algo familiar ao entrevistado dirigir-se até lá.

Um outro ponto relatado pelos participantes foi 0 fato deles reconhecerem o motivo pelo qual aquela área de Botafogo seja tão frequentada por jovens, diferente dos outros pontos de encontro dentro do mesmo bairro. Em um determinado momento do roteiro a ser seguindo, o questionado fala sobre a sua percepção sobre o público frequentador e o que os motiva a consumir no BB. De acordo com os resultados, a maioria acredita que o Baixo Botafogo seja 
o lugar onde reúne os fatores que os jovens estão buscando em momentos de lazer e descontração, são eles:

- a concentração de bares com consumação mais barata quando se comparado ao preço no próprio bairro;

- a facilidade de encontrar amigos e conhecidos mesmo sem marcar um encontro prévio;

- o ambiente familiar que o lugar tem, sem a presença de confusões ou conflitos, um diferencial importante para muitos diante da atual situação que se encontra o Estado

- e a fácil locomoção dentro e fora de Botafogo.

Muitos acreditam que pelo fato daquele público ainda não ser de fato um grupo com uma certa independência financeira, é uma forma mais barata de diversão entre eles.

\subsection{As percepções sobre o serviço}

Ao se questionar sobre os diferencias e quais as características que mais se destacavam, a categoria serviço despertou uma certa reflexão, que antes eles não tinham tido. Mesmo com a nítida certeza de que os ali presentes estavam em busca de algo mais barato, assim como eles, também conseguiram compreender que a qualidade do serviço até poderia ser inferior, se comparado a outros tipos de estabelecimentos pela cidade, porém ainda achavam o controle de mesas e do serviço do lugar bom de modo geral, o que eles entendiam como um bom custo-benefício. Em uma das entrevistas, quando abordado o assunto um dos relatos obtidos pelo cliente, foi: "não é um dos melhores, mas pelo preço vale".*

Em outra entrevista, também se pode notar que eles não estão dispostos a pagar preços absurdos quando se tem um lugar que oferece o mesmo/ou similar por um valor mais acessível, como nesse trecho citado por um dos consumidores: "Sempre tem como melhorar, mas conheço lugares piores e bem mais caros".* 


\section{5 . Conclusões}

No trabalho apresentado analisamos sob a ótica dos consumidores jovens por meio de abordagens do conceito do comportamento do consumidor ao optar e consumir em um determinado estabelecimento do Baixo Botafogo, além de tentar identificar quais são as suas percepções de valor quanto ao serviço e ambiente ali oferecidos.

Com as informações da pesquisa, foi possível identificar, primeiramente, dentro da amostra, alguns dos perfis dos consumidores que frequentam o lugar, levando em conta os pontos obtidos com uma maior expressão por parte dos mesmos.

Com relação à satisfação quanto ao lugar e ao serviço oferecido, quase não existe insatisfação pela maior parte dos consumidores envolvidos na pesquisa, e os que tiveram algo a acrescentar, sugeriram estratégias aos representantes dos bares para uma possível hipótese de melhoria no serviço de atendimento e otimização quanto ao fechamento das comandas, como a utilização de aplicativos ou softwares que já existem, agilizando os pedidos e pagamentos, já que a maioria os bares dispõem de wifi liberado para os consumidores.

Os resultados indicam que em quase sua totalidade dos entrevistados, são fortemente influenciados por parte dos amigos e pelos baixos preços dos produtos ofertados. Entende-se que por parte dos consumidores, a identificação com o ambiente familiar e amigável, é o carro-chefe de toda a expansão do Baixo Botafogo, que por sua vez, ganha esse nome justamente pela alta atratividade entre os moradores e frequentadores do bairro. Essa maneira tende a ser aplicada aos lugares com acúmulos de grandes grupos em encontros informais espalhados por toda a cidade, e ao longo de diferentes dias pela semana.

Um ponto de vista comum em alguns relatos foi a tranquilidade, por parte dos que frequentadores do lugar, quanto a assaltos, brigas ou conflitos. Distantes da realidade de Botafogo que na atualidade vem sofrendo com um alto nível de crimes, algumas das pessoas da entrevista realizada nos bares, citam 
que pelo fato de estarem "todos ali reunidos" e de "todos se conhecerem", esse tipo de incidente se torna um pouco mais difícil de acontecer entre eles.

\subsection{Sugestões pra futuras pesquisas}

Entendendo que partimos da análise de uma amostra que não consegue comprovar de fato a totalidade das opiniões por parte dos consumidores ali presentes, sugestões de pesquisas futuras e novas análises poderiam ser estudadas para melhor conseguir desenvolver tal localidade dentro do bairro.

De acordo com intervenções por parte da Prefeitura já existentes no lugar, a hipótese de se estruturar um crescimento sadio da área de maneira pensada e planejada, junto com profissionais que entendam do que a área realmente necessita, permitido a expansão dos estabelecimentos e investimentos por parte de seus administradores e melhor acomodando o seu público.

Outra sugestão seria uma pesquisa mais profunda quanto aos perfis dos consumidores que ali frequentam. Aproveitando o grande surgimento de bares com características próximas a de um determinado grupo, como por exemplo, motoqueiros, estrangeiros, bares com karaokê, surfistas, sambistas, ou esportistas. Permitiria uma provável identificação por parte dos clientes com a marca/bar e até uma possível fidelização. 


\section{Referências Bibliográficas}

ABRASEL, Associação Brasileira de Bares e restaurantes. Abrasel no Cenário Nacional. 2006. Disponível em: http://www.abrasel.com.br/index.php

BUCCI, Maria Paula Dallari. O conceito de política pública em direito. Políticas públicas: reflexões sobre o conceito jurídico. São Paulo, Saraiva, 2006.

CAMINHA, J. Botafogo e a sua evolução urbana: um restrospecto.

Disponível: http://observatoriogeograficoamericalatina.org.mx/egal14/Geografias ocioeconomica/Geografiaurbana/035.pdf

CORDEIRO, Mariana Borges. Marketing de Relacionamento para Mercado Imobiliário: Um estudo do mercado imobiliário da região central de Florianópolis. Programa de Pós-Graduação em Engenharia de Produção, Florianópolis, 2006. 164p.

Disponível em: https://repositorio.ufsc.br/ Acesso em: 20 de Junho de 2018.

CHURCHILL, Gilbert A.; PETER, J.Paul. Criando Valor para os Clientes. 2. ed., São Paulo: Saraiva, 2003.

DUMAZEDIER, Joffre. Lazer e Cultura Popular. 3. Ed., São Paulo: Perspectiva, 2009.

ENGEL, James F. Comportamento do Consumidor, 8. Ed., São Paulo: Record, 2000.

GODOY, Arilda Schmidt. Introdução à pesquisa qualitativa e suas possibilidades. Revista de Administração de Empresas, São Paulo, v. 35, n. 3, 1995.

KOTLER, Philip.; KELLER, Kelvin Lane. Administração de Marketing. 12. Ed., São Paulo: Prentice Hall, 2008.

PINHEIRO, T. e ALT, L. Design Thinking Brasil: Empatia, colaboração e experimentação para pessoas, negócios e sociedade. Rio de Janeiro: Alta Books Editora, 2017. 
Revista Veja RIO. Botafogo ganha point descolado fora do eixo tradicional. Rio de Janeiro, 19 de Janeiro de 2017.

Disponível:https://vejario.abril.com.br/cultura-lazer/botafogo-ganha-pointdescolado-fora-do-eixo-tradicional/

SANTANA, Ana Lúcia. Lazer.

Disponível: https://www.infoescola.com/sociologia/lazer/

SCHWERINER, Mario Ernesto René. Comportamento do Consumidor. São Paulo: Saraiva, 2008.

SindRio. Sindicato de Bares e Restaurantes do Rio, 2018. Disponível: http://www.sindrio.com.br/. Pesquisa feita em 15 de Junho de 2018.

SOLOMON, Michael R. O Comportamento do Consumidor. $11^{\mathrm{a}}$ Ed., Editora Saraiva, 2016. 